University of Windsor

Scholarship at UWindsor

1996

\title{
Effectiveness of social work intervention research: Internal versus external evaluations
}

Kevin M. Gorey

University of Windsor

Follow this and additional works at: https://scholar.uwindsor.ca/socialworkpub

Part of the Social Work Commons

\section{Recommended Citation}

Gorey, Kevin M.. (1996). Effectiveness of social work intervention research: Internal versus external evaluations. Social Work Research, 20 (2), 119-128.

https://scholar.uwindsor.ca/socialworkpub/22

This Article is brought to you for free and open access by the School of Social Work at Scholarship at UWindsor. It has been accepted for inclusion in Social Work Publications by an authorized administrator of Scholarship at UWindsor. For more information, please contact scholarship@uwindsor.ca. 


\title{
Effectiveness of social work intervention research: Internal versus external evaluations
}

\author{
Kevin M. Gorey
}

This meta-analytic review synthesizes the findings of 88 recent (1990 to 1994) independent studies of the effectiveness of social work interventions and compares the findings of those studies based on authors' assessments of their practice experience (internal evaluations) and other evaluators' assessments (external evaluations). Overall, social work interventions are effective; three-quarters of the clients who participate in social work interventions do better than the average client who does not. Also, the estimated rate of problem improvement among clients who experience an intervention and are assessed by social worker-researchers themselves is nearly 25 percent greater than the estimated rate assessed by other evaluators. Internal evaluations, which arise from workers' day-to-day assessments of their own practice and account for the vast majority of social work's knowledge base, may be thought to precede external ones. However, at some point in the development of knowledge, external evaluation may enhance confidence in the effectiveness of an intervention.

\section{Key words: bias; effectiveness; evaluation; meta-analysis; social work practice}

Kevin M. Gorey, PbD, MSW, is assistant professor, School of Social Work, University of Windsor, 401 Sunset Avenue, Windsor, Ontario, Canada N9B 3P4; e-mail: gorey@server.uwindsor.ca. $\mathrm{n}$ an era of political and fiscal conservatism in which cutting social welfare programs heads the agendas of most legislative bodies in North America, the question of social work's effectiveness is of paramount importance. Integrative empirical evidence is needed to continually demonstrate the profession's valuable contribution to the process of solving personal problems in living as well as larger social problems, especially to cogently refute the colloquial, stereotypical image of social workers as well-meaning but largely ineffective home visitors. This review of the effectiveness of social work interventions from studies done in the early 1990 s replicates the findings of similar summaries from the 1970s and 1980s (Reid \& Hanrahan, 1982; Rubin, 1985; Videka-Sherman, 1988)-that, in general, social work methods are effective. However, this review's findings also form the basis for a caveat that has not been reported by previous reviewers in this field-that social workers, like all other professionals, naturally evaluate their work in accord with personal, subjective standards. This article demonstrates this principle by comparing studies based on workers' assessments of their practice experience (internal evaluations) versus assessments by other evaluators (external evaluations) and asks two questions: (1) Are social work interventions effective? and (2) Do internal evaluators more favorably assess the effectiveness of their practice than external evaluators? I hypothesized that the average effect among internal evaluations would be significantly larger than that observed among external evaluations.

\section{REVIEWS OF SOCIAL WORK'S EFFECTIVENESS}

Before Videka-Sherman's (1988) meta-analysis, the reviews in this field were based on vote-count methods of summarization and focused almost exclusively on the issue of statistical significance (Hedges \& Olkin, 1982). For example, the two earliest reviews of direct social work practice from the 1930 s to the early 1970 s found only eight of 32 effects statistically significant and so inferred the general ineffectiveness of social work 
methods (Fischer, 1973; Wood, 1978). On the other hand, more recent, similarly constructed reviews inferred social work's general effectiveness from their observation of 29 of 34 statistically significant effects (Reid \& Hanrahan, 1982; Rubin, 1985). Similar early nonsignificant statistical findings and more promising recent ones have also been observed among the allied fields of psychotherapy, marital and family therapy, and behavioral therapy (Thomlison, 1984).

These reviews have provided a service to the social work profession by summarizing 50 years of research. Nonetheless, in terms of the significance of the published findings, they have merely concluded, for example, that the play of chance or random sampling variability does not explain the recent observed group differences of social work interventions versus comparison conditions. The ability to rule out chance as a potential alternative explanation for social work's hypothesized effectiveness is an important step, but only a first step, in knowledge building. To put this reasoning into context, one may ask, "What decisions would you be comfortable making as a worker, supervisor, or agency executive based on such information" (for example, that "the interventive method is effective, $p<$ $.001 ")$ ? Most social workers want more information about the magnitude of the intervention's effect or its effect size, which is more directly related to its clinical or policy significance.

In the most recent review in this field, VidekaSherman (1988) used meta-analytic techniques to summarize research in direct mental health practice from 1965 to 1983 . Through estimation of the size and direction of each study's reported interventive effect, the study made inferences more relevant to social work's clinical significance and more useful for grappling with cost-benefit concerns. For example, averaging across 61 studies, two-thirds $\left(U_{3}=66.4\right.$ percent; Cohen, 1988 ) of the clients who experienced social work interventions did better (for example, on measures of problem improvement) than the average client in comparison conditions $(p<.001$, combined probability [Rosenthal, 1978] based on a secondary analysis of Videka-Sherman's data). Such effect size analysis of clinical as well as statistical significance is more germane than traditional review strategies to the summary of social work research findings.

The scientist-practitioner model, based on quantitative, rational, and empirical ways of knowing, has been proposed to bring objectivity to the evaluation of practice (Gibbs, 1983; Grinnell, 1983; Karger, 1983). Objections to the application of this model to social work research have been raised, including its diminishment of the importance of the unique, subjective, ex- istential encounter of each worker and client; the relative inflexibility of its methods; and its subjugation of social work and client values to the purported valueneutral domain of science (Caspi, 1992; Dean \& Fenby, 1989; Gilgun, 1992; Goldstein, 1991; Heineman, 1981; Kondrat, 1992; Smith, 1987; Tyson, 1992). Whatever side one may take in the debate, the practical center of this issue involves social work's commitment to evaluation and advancing the profession's knowledge base (Canadian Association of Social Workers, 1994; NASW, 1994).

However, if the findings of such evaluations are to be convincing to potential critics and political adversaries, who ought to perform them? This methodological issue has implications for the valid evaluation of social work practice. For example, in a review of the interdisciplinary research on direct and indirect intervention effectiveness in long-term care settings, Cryns, Gorey, and Brice (1989) found that the magnitude of the average effect reported by researchers affiliated with the institutions being evaluated was twice as large as the estimated effect based on external evaluations. Although this gerontological literature was interdisciplinary in perspective and none of the review outcomes were grouped by profession, much of the work was accomplished by social workers. It seems likely that this data trend could be replicated in any discipline, including social work.

\section{METHOD}

\section{Study Selection}

The target population of this review were studies that reported the findings of recent (1990 to 1994) social work research. The studies were retrieved from prestigious (publication acceptance rate of 50 percent or less and indexed or abstracted by four or more services), peer-reviewed professional (affiliated with a professional social work association) journals listed in Mendelsohn's (1992) An Author's Guide to Social Work Journals (3rd edition). Eight social work journals met the criteria: Australian Social Work, British Journal of Social Work, Canadian Social Work Review, Health of Social Work, Journal of Social Work Education, Social Work, Social Work in Education, and Social Work Research (formerly Social Work Research o Abstracts). To reflect the two prevalent fields of practice and concentration areas offered by graduate schools of social work-aging and family practice-two prestigious multidisciplinary journals were included: Gerontologist and Journal of Family Issues. Also, reviewers of a draft of this article suggested the inclusion of three researchoriented journals that meet the criteria but were not 
affiliated with any professional association: Journal of Social Service Research, Research on Social Work Practice, and Social Service Review. A review of the 13 journals produced 2,273 studies (excluding editorials, reviews, notes, or commentaries) from which a sample of studies related to social work's effectiveness were selected.

The key words from an article's title or abstract used for the search were assessment, benefit, effect, effectiveness, efficacy, evaluation, follow-up, or outcome. The search was not restricted by level of intervention; individual, small-group, family, program (agency or institution level), and community interventions were included. However, among the interdisciplinary journals, purely biomedical interventions were excluded. A total of 279 studies were retrieved. Of these, only 88 (31.5 percent) were operationalized such that an indication of their effect size was calculable (see "Studies Reviewed"). That only one of every eight articles in the social work literature refers at all to effectiveness is discouraging (see also Cheetham, 1992; Jenkins, 1987; Makris, 1987).

The 191 conceptually relevant but empirically deficient studies were excluded because they did not report within-group variability descriptors (for example, group standard deviations) or statistics that account for such phenomena (for example, $F$ ratio, $t$ test, or $\left.\chi^{2}\right)$. Average between-group differences are uninterpretable without such information. For example, the estimated effect size ( $r$ index) from a hypothetical intervention to alleviate depression-intervention group (mean depression score $=20.0$ ) versus comparison group (mean $=15.0$ )-is .45 if the two group's average standard deviation is 5.0 but only .12 if their average standard deviation is 20.0 . These 191 studies were also not found to differ significantly from the 88 included studies on first author's affiliation: 58.1 percent versus 51.1 percent were internal evaluations, respectively $\left[\chi^{2}(1, N=279)=1.19\right.$, not significant $]$.

\section{Data Analysis}

A scale-free metric or effect size-the $r$ index, which is calculable and interpretable as the Pearson's linear correlation coefficient and estimates the strength of the social work intervention-outcome relationshipwas calculated for each of the 88 studies (Cooper, 1989; Glass, McGaw, \& Smith, 1981; Rosenthal, 1984; Wolf, 1986). Pearson's $r$ is calculable from a variety of outcome statistics and thus allows for ease of across-study comparison and summary. Because the majority of the studies in the social work field are not true experiments (the assessment of a hypothesized causal interventionoutcome relationship), an effect size index that focuses on the strength of the intervention-outcome association was deemed most appropriate.

The studies included in this review were not necessarily highly quantitative in their approach. For example, a hypothetical study that dichotomized a worker-client constructed scale of problem improvement and found 40 of 50 intervention group clients improved versus 20 of 50 comparison group clients $\left[\chi^{2}(1, N=100)=16.67, p<.001\right]$ would produce an $r$ index estimate of $.408\left[r=\left(\chi^{2} / n\right)^{1 / 2}\right]$.

Effects were averaged across operational measures within studies (for example, two measures of depression reported in a study were averaged to produce one review outcome). Next, $r$ indexes were averaged within institutional affiliation domain (that is, internal versus external evaluations), and the between-group mean difference was compared using an independent-samples $t$ test. The overall statistical significance of each domain was also estimated by the method of unweighted probabilities (Rosenthal, 1978). Among the groupdesign studies included in the analysis, sample size was not found to be associated with effect size, so the across-study combined probabilities were not weighted by individual study sample size.

Effect sizes were calculated blindly. A coder worked from only the "Results" sections of photocopied manuscripts; all information about authorship and institutional affiliations was excluded. Three coders independently rated each manuscript as an internal or external evaluation. The average agreement among the coders was 95.5 percent. An internal evaluation was operationally defined as any study in which the first author was employed by any of the agencies or institutions where the research was carried out or in which the first author was engaged in practice with the clients participating in the study (data extracted from institutional affiliation and "Methods" sections). All of the remaining studies, for example, those in which the first author had solely an academic affiliation, were defined as external evaluations. However, studies authored by academics serving as supervisors of the study's student practitioners and studies that were funded by participating agencies, regardless of the author's affiliation, were deemed internal evaluations.

\section{RESULTS}

\section{Sample Description}

Of the 88 studies, 49 (55.7 percent) had sample sizes of fewer than 100 client-participants (median = 68 , combined groups for both intervention and comparison, range $=16$ to 13,592 , excluding the nine single-system designs). Sixty-four (72.7 percent) 
evaluated direct, face-to-face interventions with individuals, small groups, or families, and the remainder evaluated programs or agencies (although the studies were typically based on needs, problems, issues, and concerns identified and evaluated in face-to-face activities). The direct practice interventions were usually brief (median $=$ eight weeks, range $=$ one to 24 weeks); however, only 46 (71.9 percent) studies reported valid data on this variable.

Thirty-nine ( 44.3 percent) reported sufficient information to estimate average client mortality, attrition, or loss to follow-up of nearly one-quarter (median $=24.0$ percent, range $=2.0$ percent to 63.0 percent). Thirty-five (39.8 percent) included a follow-up assessment, which was typically at slightly less than one year after the initial intervention termination (median $=$ eight months, range $=$ two to 120 months) .

\section{Design, Intervention, and First-Author Characteristics}

Seventy-nine ( 89.8 percent) of the 88 studies used group designs (Table 1). Of these, 53 (67.1 percent) fell short of experimental categorization; even among those in the experimental category (which implies random assignment to the intervention or control group conditions), there was no mention of blinding procedures. Not surprisingly, given typical practice constraints, only nine studies ( 10.2 percent) used random selection of their samples. A variety of outcome measures, including standardized (43.2 percent), individualized ( 38.6 percent), and archival ( 14.8 percent), were used to assess the effectiveness of direct practice $(n=$ $64,72.7$ percent) and program ( $n=24,27.3$ percent) interventions.

First authors, who typically maintain primary editorial control of their manuscripts, were predominantly social workers ( 84.0 percent) with doctoral degrees ( 85.7 percent). Of the studies that coded such information, nearly all of the work or intervention implementation was accomplished by social workers with $\mathrm{MSW} / \mathrm{MA}$ or $\mathrm{PhD} / \mathrm{DSW}$ degrees.

\section{Main Effect of Social Work Intervention}

Combining the results of all 88 studies without regard to internal-external status, this review calculated the general effectiveness of social work interventions as follows: mean $r$ index $=.356, S D=.261, p<.001$. Conversion to Cohen's (1988) $U_{3}$ statistic allows for the inference that 77.7 percent of the clients who participated in an intervention did better than the average client who did not. Overall, this review replicates the findings of Videka-Sherman's (1988) meta-analysis $(r=.214$, converted from Cohen's $d$ index, which
Table 1-Descriptive Profile of the 88 Studies

\begin{tabular}{|c|c|c|}
\hline Characteristic & $n$ & $\%$ \\
\hline \multicolumn{3}{|l|}{ Design characteristic } \\
\hline \multicolumn{3}{|l|}{ Group design } \\
\hline Pre-experimental & 28 & 31.8 \\
\hline Quasi-experimental & 25 & 28.4 \\
\hline Experimental & 26 & 29.5 \\
\hline Single-system design ${ }^{a}$ & 9 & 10.2 \\
\hline \multicolumn{3}{|l|}{ Comparison group ${ }^{b}$} \\
\hline Standard/alternative & 27 & 52.9 \\
\hline Waiting list & 13 & 25.5 \\
\hline No intervention & 11 & 21.6 \\
\hline Random selection used & 9 & 10.2 \\
\hline \multicolumn{3}{|l|}{ Outcome measures } \\
\hline Standardized ${ }^{c}$ & 38 & 43.2 \\
\hline Individualized to problem ${ }^{\mathrm{d}}$ & 34 & 38.6 \\
\hline Archival $^{e}$ & 13 & 14.8 \\
\hline Client satisfaction & 3 & 3.4 \\
\hline
\end{tabular}

Intervention characteristic

Level of the intervention ${ }^{f}$

$\begin{array}{lr}\text { Small group } & 35 \\ \text { Program/communityg } & 24 \\ \text { Individual } & 20 \\ \text { Family } & 9\end{array}$

First-author characteristic

Profession $^{\mathrm{h}}$

Social work

Other $^{\mathrm{i}}$

Highest degree achieved

$\mathrm{PhD} / \mathrm{DSW}$

48

MSW/MA

8

${ }^{2}$ Three $\mathrm{AB}$ designs, four $\mathrm{ABAB}$, and two multiple baselines; range $=1$ to 11 clients, median $=4$ clients.

${ }^{\mathrm{b}}$ Coded for 51 studies with comparison or control groups (quasi-experimental and experimental).

'Standardized = existing psychosocial measures with established indices of reliability and validity.

${ }^{\mathrm{d}}$ Individualized $=$ measures unique to the study and client. ${ }^{\mathrm{c}}$ Archival $=$ measures from archival or other third-person sources.

Interventions were represented among a variety of theoretical, field-of-practice, and problem domains, including generalist $(47.7 \%)$; child and family $(43.2 \%)$, health and disability (39.8\%), and aging (17.0\%); family $(39.8 \%)$, mental $(28.4 \%)$, social $(22.7 \%)$, and physical health $(9.1 \%)$; family violence $(8.0 \%)$, elder caregiving $(5.7 \%)$, chronic mental illness/drugrelated problems/family preservation ( $4.5 \%$ each), and AIDS $(3.4 \%)$. Effect size was not found to differ significantly by any of the groupings.

${ }^{\text {BT }}$ Twenty-two agency-level program evaluations and 2 community-level evaluations.

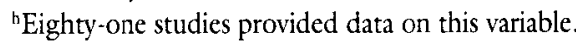

'About equally distributed among psychology, psychiatry, nursing, and educational counseling.

'Fifty-six studies provided data on this variable. 
was the effect size metric used by Videka-Sherman; $U_{3}$ $=66.4$ percent, $p<.001)$. However, the range of observed $r$ values was quite large $(-.380$ to .962$)$. In fact, the 88 primary study effects were significantly more heterogeneous than would be expected due to random sampling variability $\left[\chi^{2}(87, N=88)=315.89, p\right.$ $<.001]$ (Hedges \& Olkin, 1985). Institutional auspices accounted for a significant proportion of this between-study variability in observed effectiveness.

Internal versus External Evaluations. The mean effect size among the 45 internal evaluations $(r=.518)$ was significantly larger than that among the 43 external evaluations $(r=.186)[t(86)=7.93, p<.001]$ (Table 2). However, if each group of studies-internal or external - were treated as an independent review of social work's intervention effectiveness, they would reach the same conclusion. Both internal and external evaluators similarly concluded social work's intervention effectiveness $(p<.001)$, but the former estimated a larger clinical effect than the latter. For example, the rate of problem improvement among clients who experienced an intervention condition and were assessed by the social workers themselves was nearly 25 percent greater than the rate of improvement among similar clients assessed by another evaluator $\left(U_{3}\right.$ difference $\left.=.887-.647=.240\right)$.

Adjunct Regression Analyses. This review also explored the relationships of other coded study characteristics to the estimated size of the interventive effect. Single-system designs reported an average interventive effect $(r=.664)$ significantly greater than that of group designs $(r=.321)[t(86)=3.74, p<$ $.001]$. Eight of the nine single-system studies were also categorized as internal evaluations, so this variable does

\section{Table 2-Average Effect Sizes, by Internal Versus External Evaluations}

\begin{tabular}{lcc}
\hline Effect Size Statistic & $\begin{array}{c}\text { Internal } \\
\text { Evaluation } \\
(\boldsymbol{n}=45)\end{array}$ & $\begin{array}{c}\text { External } \\
\text { Evaluation } \\
(\boldsymbol{n}=43)\end{array}$ \\
\hline Minimum $r$ & .160 & -.380 \\
Maximum $r$ & .962 & .558 \\
Mean $r^{2}$ & .518 & .186 \\
$S D$ & .218 & .173 \\
$95 \%$ confidence interval & $.454, .582$ & $.134, .238$ \\
Cohen's $U_{3}(\%)$ & 88.7 & 64.7 \\
\hline
\end{tabular}

${ }^{\mathrm{a} C o m b i n e d ~ p r o b a b i l i t y ~ b y ~ t h e ~ m e t h o d ~ o f ~ a d d i n g ~} z s, p<.001$. For internal evaluation, all 45 studies, $p<.05$. For external evaluations, 27 studies, $p<.05 ; 2$ studies, $p<.10 ; 12$ studies, nonsignificant; and 2 studies, $p<.05$, but counterhypothetical. not add substantially to the explanation of social work intervention effectiveness (it did not enter a stepwise regression of effect size on institutional affiliation). None of the other descriptive characteristics were found to be associated with study effect size or with author's institutional affiliation. In addition, characteristics of nonfirst authors were not associated with intervention effect size. The institutional affiliation-assessed interventive effect relationship $\left(R^{2}=.383\right.$, adjusted for single-system design status) seems robust to the potentially moderating influence of other study characteristics and to be a function solely of first-author affiliation.

Two other methodological characteristics' associations with interventive effect size approached significance $(p<.10)$ : design rigor and sample size. After all three methodological characteristics were forced into the model [single-system or group design, $\beta=.167$; design rigor, $\beta=.049$; sample size, $\beta=-.295 ; R^{2}=$ $.299 ; F(3,84)=11.95, p<.001]$, the institutional affiliation variable still entered in a stepwise fashion $[\beta$ $=.533$; total model $R^{2}=.549 ; F(4,83)=25.27, p<$ $.001]$ and accounted for nearly half of the criterion variance explained by the model. Perhaps the most instructive trend elucidated by this regression model is that after other factors are accounted for, there is a tendency for more rigorous research designs (for example, randomized experiments) to more favorably evaluate social work interventions.

\section{Review Limitations}

The findings of this review may be confounded by selection bias. Nearly all ( 85.3 percent) of the 88 studies were selected from peer-reviewed journals affiliated with professional social work associations, and most of the first authors ( 84.0 percent) were social workers. Less than half ( 40.7 percent) of the studies selected for inclusion in the five previous reviews in this field (Fischer, 1973; Reid \& Hanrahan, 1982; Rubin, 1985; Videka-Sherman, 1988; Wood, 1978) were from peerreviewed journals; more than one-quarter (27.4 percent) were from nonrefereed books, monographs, and conference proceedings, and one-third (31.9 percent) were from journals affiliated with psychiatric and psychological associations. Selection bias can affect the current review's question about the different inferences made by internal and external evaluators.

However, no empirical basis for such concern was found. Subsample analyses on only those studies reported in the 11 social work journals or only those in which the first author was a social worker found the same substantive difference between internal and external evaluators. In fact, the exclusion of any one of 
the 13 journals made no substantive difference in the review's findings. The replication of this review's findings across subsamples greatly diminishes the potency of selection as an alternative explanation. Others are invited to further test this review's external validity by replicating it with other samples of journals.

Second, because this review was based on published research, the findings may be confounded by publication bias. Rosenthal's (1979) fail-safe $N$ (the estimated number of studies with null findings indicative of ineffectiveness that would have to exist in worker's "file drawers" [completed nonpublished or nonsignificant work] to change this review's conclusion of social work's effectiveness) at $p<.05$ for the overall finding of social work's effectiveness was found to be 1,785 . The fail-safe $N$ is more than 20 times the number of retrieved studies included in this review $(n=88)$. Its overall finding seems highly resistant to the potential impact of unretrieved null results.

Third, information bias may intrude due to the misclassification of studies (either internal or external evaluation). This review was based on the assumption that external evaluators are more disinterested in the magnitude of their evaluation outcomes than are internal evaluators. However, some external evaluators, by virtue of receipt of a consulting fee, for example, may be personally invested in a given evaluation outcome. Such studies would more validly be coded as internal. Furthermore, such misclassification is not readily discernible because the type of information necessary for its assessment is almost never reported. It is clear, however, that this type of misclassification error tends to attenuate any observed difference between the reported average effect size of internal and external evaluations (Copeland, Checkoway, \& McMichael, 1977; Flegal, Brownie, \& Haas, 1986). For example, if five of the sample of studies coded as external evaluations (hypothesized smaller effect size) were really internal evaluations (hypothesized larger effect size), this review's central finding concerning the difference between them would be biased. The true between-group difference would likely be even larger than that estimated by this meta-analysis. To the extent that this type of error intrudes, this review's central finding underestimates the true difference between internal and external evaluators.

\section{DISCUSSION}

More than three-quarters ( $U_{3}=77.7$ percent) of clients participating in an intervention do better than the average client who does not. This finding closely replicates that of an earlier meta-analysis in the social work field (Videka-Sherman, 1988). In addition, in- ternal evaluators tend to more favorably evaluate their practice ( $U_{3}=88.7$ percent) than external evaluators ( $U_{3}=64.7$ percent). This new finding represents a caveat for those who use the results of social work research to make policy- and practice-related decisions. The first author's institutional affiliation should be considered when critically examining and synthesizing social work intervention research findings.

This review did not restrict itself to type of social work practice or evaluation design; therefore, it allowed for the exploration of their potentially moderating impact on the main intervention effect. No such effects were observed. For example, the average effect size observed across the 88 studies did not differ significantly by direct practice versus program evaluation; experiments versus other group designs; and type of comparison, control group condition, or standardized outcome measures of a quantitative nature versus individualized measures of a qualitative nature. This review did not provide any measure of control for alternative third-variable explanations that were not present in the 88 studies. However, the consistent replication of its central finding across measures, research designs, and intervention levels supports a causal explanation for the observed social work intervention-problem amelioration relationship. Finally, as Videka-Sherman (1988) also found, subsample analyses by specific demographic or other characteristics of clients and workers or by specific intervention characteristics were not possible because of the lack of valid data reported in the studies.

Social workers evaluating their own direct practice or their agencies' programs tend to report more favorable findings than evaluators who are not directly involved in the work. However, social work's effectiveness was the same whether based on internal or external evaluations. Also, the internal-external dichotomy itself may be better thought of as options along a continuum of knowledge progression. Internal evaluations may be thought to naturally precede external ones.

The vast majority of social work's knowledge base arises from workers' day-to-day evaluation of their own practice experiences. The findings of this review do not diminish the importance of such internal evaluation. The findings do, however, suggest that at some point in the development of knowledge, disinterested or external evaluation will greatly enhance confidence in an intervention's effectiveness. Such external evaluation may be implemented, for example, before suggesting its generalizability to many more clients at other agencies or before policy decisions are made that involve a great deal of funding and investment of human resources. Agency liaisons with universities, 
specifically with graduate schools of social work, could help meet this need, and indeed the call for such a relationship has been made by others (Epstein, 1990; Estes, 1992).

A final suggestion stems from this review's descriptive findings. To be able to share social work's day-today practice experiences in a way that will be truly helpful, more detail on client, worker, and intervention characteristics is needed in research reports. This suggestion echoes Videka-Sherman's (1988) lament that studies are nearly devoid of such information. In addition, this review found little information pertinent to the methods in the interventions. As other disciplines move to more specific inquiry, so must social work.

\section{CONCLUSION}

As a matter of scientific and political pragmatism, social workers ought to include external evaluation methods at some stage in the knowledge-building process. In fact, in today's political climate, there is an ethical imperative for social workers to do so; otherwise, the funding for effective social work programs and services may be cut from municipal, regional, and federal budgets. If social work does not develop and maintain the action plans necessary to keep highly effective social workers on the front line, then despite their potential knowledge and skill, social work as a profession will be ineffective. Social workers ought not be shy about doing this; the more rigorously professional social work methods are evaluated, the better they appear.

\section{REFERENCES}

Canadian Association of Social Workers. (1994). Social work code of ethics. Ottawa: Author.

Caspi, Y. (1992). A continuum theory for social work knowledge. Journal of Sociology and Social Welfare, 19, 105120.

Cheetham, J. (1992). Evaluating social work effectiveness. Research on Social Work Practice, 2, 265-287.

Cohen, J. (1988). Statistical power analysis for the behavioral sciences (2nd ed.). Hillsdale, NJ: Lawrence Erlbaum.

Cooper, H. M. (1989). Integrating research: A guide for literature reviews (2nd ed.). Newbury Park, CA: Sage Publications.

Copeland, K. T., Checkoway, H., \& McMichael, A. J. (1977). Bias due to misclassification in the estimation of relative risk. American Journal of Epidemiology, 105, 488-495.

Cryns, A., Gorey, K., \& Brice, G. (1989, November). Long-term care outcome research as a function of researcher location: A comparative analysis. Paper presented at the 42nd annual scientific meeting of the Gerontological Society of America, Minneapolis.

Dean, R. G., \& Fenby, B. L. (1989). Exploring epistemologies: Social work action as a reflection of philosophical assumptions. Journal of Social Work Education, 25, 4654.

Epstein, W. M. (1990). Rational claims to effectiveness in social work's critical literature. Social Science Journal, 27, 129145.
Estes, R. J. (1992). Enhancing practice effectiveness: The social work practice agenda. Jewish Social Work Forum, 28, 5 23.

Fischer, J. (1973). Is casework effective? A review. Social Work, $18,5-20$.

Flegal, K. M., Brownie, C., \& Haas, J. D. (1986). The effect of exposure misclassification on estimation of relative risk American Journal of Epidemiology, 123, 736-751.

Gibbs, L. (1983). Evaluation research: Scientist or advocate? Journal of Social Service Research, 7, 81-92.

Gilgun, J. F. (1992). Hypothesis generation in social work research. Journal of Social Service Research, 15, 113 135.

Glass, G. V., McGaw, B., \& Smith, M. L. (1981). Meta-analysis in social research. Beverly Hills, CA: Sage Publications.

Goldstein, H. (1991). Qualitative research and social work practice: Partners in discovery. Journal of Sociology and Social Welfare, 18, 101-119.

Grinnell, R. M., Jr. (1983). Quantitative articles in social work journals: A research note. Arete, 8, 33-38.

Hedges, L., \& Olkin, I. (1982). Vote-counting methods in research synthesis. Psychological Bulletin, 88, 359-369.

Hedges, L., \& Olkin, I. (1985). Statistical methods for meta analysis. Orlando, FL: Academic Press.

Heineman, M. B. (1981). The obsolete scientific imperative in social work research. Social Service Review, 55, 371-397.

Jenkins, S. (1987). The limited domain of effectiveness research. British Journal of Social Work, 17, 587-594.

Karger, H. J. (1983). Science, research, and social work: Who controls the profession? Social Work, 28, 200-205.

Kondrat, M. E. (1992). Reclaiming the practical: Formal and substantive rationality in social work practice. Social Service Review, 66, 237-255.

Makris, D. M. (1987). An assessment of core social work journals from 1980 to 1985 with particular reference to research and practice implications. Master's thesis, University of Windsor, Windsor, Ontario.

Mendelsohn, H. N. (1992). An author's guide to social work journals (3rd ed.). Washington, DC: NASW Press.

National Association of Social Workers. (1994). NASW code of ethics. Washington, DC: Author.

Reid, W. J., \& Hanrahan, P. (1982). Recent evaluations of social work: Grounds for optimism. Social Work, 27, 328-340.

Rosenthal, R. (1978). Combining results of independent studies Psychological Bulletin, 85, 185-193.

Rosenthal, R. (1979). The "file drawer problem" and tolerance for null results. Psychological Bulletin, 86, 638-641.

Rosenthal, R. (1984). Meta-analytic procedures for social research. Beverly Hills, CA: Sage Publications.

Rubin, A. (1985). Practice effectiveness: More grounds for optimism. Social Work, 30, 469-476.

Smith, D. (1987). The limits of positivism in social work research. British Journal of Social Work, 17, 401-416.

Thomlison, R. J. (1984). Something works: Evidence from practice effectiveness studies. Social Work, 29, 51-57.

Tyson, K. B. (1992). A new approach to relevant scientific research for practitioners: The heuristic paradigm. Social Work, 37, 541-556.

Videka-Sherman, L. (1988). Meta-analysis of research on social work practice in mental health. Social Work, 33, 325-338.

Wolf, F. M. (1986). Meta-analysis: Quantitative methods in research synthesis. Beverly Hills, CA: Sage Publications.

Wood, K. M. (1978). Casework effectiveness: A new look at the research evidence. Social Work, 23, 437-458.

\section{STUDIES REVIEWED}

Auslander, G. K., \& Soskolne, V. (1993). The administrative and posthospital care outcomes of discharge planning: Preliminary results of an experimental intervention. Journal of Social Service Research, 17, 99-117. 
Barber, J. G. (1992). Evaluating parent education groups: Effect on sense of competence and social isolation. Research on Social Work Practice, 2, 28-38.

Béliveau, G., \& Deslandes-Senay, R. (1994). L'informatique et l'enseignement du service social: le tardem de l'avenir [The use of computers in social services: The way of the future]. Canadian Social Work Review, 11, 27-51.

Benbenishty, R., Ben-Zaken, A., \& Yekel, H. (1991). Monitoring interventions with young Israeli families. British Journal of Social Work, 21, 143-155.

Berry, M. (1992). An evaluation of family preservation services: Fitting agency services to family needs. Social Work, 37, 314-321.

Bielenberg, L. T. (1991). A task-centered preventive group approach to create cohesion in the new stepfamily: A preliminary evaluation. Research on Social Work Practice, 1, 416-433.

Blankertz, L. E., \& Cnaan, R. A. (1992). Principles of care for dually diagnosed homeless persons: Findings from a demonstration project. Research on Social Work Practice, 2, 448-464.

Blankertz, L. E., \& Cnaan, R. A. (1994). Assessing the impact of two residential programs for dually diagnosed homeless individuals. Social Service Review, 68, 536-560.

Carlo, P. (1993). Parent education vs. parent involvement: Which type of efforts work best to reunify families? Joumal of Social Service Research, 17, 135-150.

Ciffone, J. (1993). Suicide prevention: A classroom presentation to adolescents. Social Work, 38, 197-203.

Cooper, M. (1990). Treatment of a client with obsessivecompulsive disorder. Social Work Research \& Abstracts, 26(2), 26-32.

Dallaire, N., \& Chamberland, C. (1994). La pertinence du programme parents efficaces auprès de parents bénéficiant du soutien d'un groupe parentraide: Une étude préliminaire [The effectiveness of parent groups: A preliminary investigation]. Canadian Social Work Review, $11,67-88$.

Derezotes, D. S., \& Barth, R. P. (1993). Adolescent maltreatment prevention. Social Work in Education, 15, 151-166.

Dziegielewski, S. F. (1991). Social group work with the family members of elderly nursing home residents with dementia: A controlled evaluation. Research on Social Work Practice, 1, 358-370.

Edleson, J. L., \& Syers, M. (1991). The effect of group treatment for men who batter: An 18-month follow-up study. Research on Social Work Practice, 1, 227-243.

Feldman, P. H. (1993). Work life improvements for home care workers: Impact and feasibility. Gerontologist, 33, 47-54.

Fielden, M. A. (1990). Reminiscence as a therapeutic intervention with sheltered housing residents: A comparative study. British Journal of Social Work, 20, 21-44.

Flowers, J. V., Miller, T. E., Smith, N., \& Booraem, C. D. (1994). The repeatability of a single-session group to promote safe-sex behavior in a male at-risk population. Research on Social Work Practice, 4, 240-247.

Franklin, C., McNeil, J. S., \& Wright, R., Jr. (1990). School social work works: Findings from an alternative school for dropouts. Social Work in Education, 12, 177-194.

Frey, D. E., Kelbey, T. J., Durham, L., \& James, J. S. (1992). Enhancing the self-esteem of selected male nursing home residents. Gerontologist, 32, 552-557.

Gammon, E. A., \& Rose, S. D. (1991). The coping skills training program for parents of children with developmental disabilities: An experimental evaluation. Research on Social Work Practice, 1, 244-256.

Gibbons, J. (1991). Children in need and their families: Outcomes of referral to social services. British Journal of Social Work, 21, 217-227.

Goldapple, G. C., \& Montgomery, D. (1993). Evaluating a behaviorally based intervention to improve client retention in therapeutic community treatment for drug dependency. Research on Social Work Practice, 3, 21-39.

Goodman, C. (1990). Evaluation of a model self-help telephone program: Impact on natural networks. Social Work, 35, $556-562$.

Green, R. G., \& Vosler, N. R. (1992). Issues in the assessment of family practice: An empirical study. Journal of Social Service Research, 15, 1-19.

Hanson, M., Cancel, J., \& Rolon, A. (1994). Reducing AIDS risk among dually disordered adults. Research on Social Work Practice, 4, 14-27.

Hanson, M., Foreman, L., Tomlin, W., \& Bright, Y. (1994). Facilitating problem drinking clients' transition from inpatient to outpatient care. Health \& Social Work, 19 , 23-28.

Harkness, D., \& Hensley, H. (1991). Changing the focus of social work supervision: Effects on client satisfaction and generalized contentment. Social Work, 36, 506-512.

Hawkins, J. D., Jenson, J. M., Catalano, R. F., \& Wells, E. A. (1991). Effects of a skills training intervention with juvenile delinquents. Research on Social Work Practice, $1,107-121$.

Hepler, J. B. (1994a). Evaluating the effectiveness of a social skills program for preadolescents. Research on Social Work Research, 4, 411-435.

Hepler, J. B. (1994b). Mainstreaming children with learning disabilities: Have we improved their social environment? Social Work in Education, 16, 143-154.

Hetzel, S., Wilkins, V., Carrig, H., Thomas, J., \& Senior, P. (1993). An evaluation of caller satisfaction with solutionfocused telephone counselling. Australian Social Work, 46, 51-55.

Hornbrook, M. C., Stevens, V. J., Wingfield, D. J., Hollis, J. F., Greenlick, M. R., \& Ory, M. G. (1994). Preventing falls among community-dwelling older persons: Results from a randomized trial. Gerontologist, 34, 16-23.

Hugen, B. (1993). The effectiveness of a psychoeducational support service to families of persons with a chronic mental illness. Research on Social Work Practice, 3, 137 154.

Ingersoll-Dayton, B., Chapman, N., \& Neal, M. (1990). A program for caregivers in the workplace. Gerontologist, 30, 126-130.

Jensen, C. (1994). Psychosocial treatment of depression in women: Nine single-subject evaluations. Research on Social Work Practice, 4, 267-282.

Kissman, K. (1992). Parent skills training: Expanding schoolbased services for adolescent mothers. Research on Social Work Practice, 2, 161-171.

Larkin, J. P., \& Hopcroft, B. M. (1993). In-hospital respite as a moderator of caregiver stress. Health \& Social Work, 18 132-138.

Lee, J. H., \& Holland, T. P. (1991). Evaluating the effectiveness of foster parent training. Research on Social Work Practice, 1, 162-174.

Leirer, V. O., Morrow, D. G., Tanke, E. D., \& Pariante, G. M. (1991). Elders' nonadherance: Its assessment and medication reminding by voice mail. Gerontologist, 31 , 514-520.

Lie, G.-Y., \& Moroney, R. M. (1992). A controlled evaluation of comprehensive social services provided to teenage mothers receiving AFDC. Research on Social Work Practice, 2, 429-447.

Lipton, H. L., \& Bird, J. A. (1994). The impact of clinical pharmacists' consultations on geriatric patients' compliance and medical care use: A randomized controlled trial. Gerontologist, 34, 307-315.

Luptak, M. K., \& Boult, C. (1994). A method for increasing elders' use of advance directives. Gerontologist, 34, 409412 . 
Magen, R. H., \& Rose, S. D. (1994). Parents in groups: Problem solving versus behavioral skills training. Research on Social Work Practice, 4, 172-191.

Mancoske, R. J., Standifer, D., \& Cavley, C. (1994). The effectiveness of brief counseling services for battered women. Research on Social Work Practice, 4, 53-63.

McMurtry, S. L. (1992). Evaluating efforts to free foster children for adoption. Journal of Social Service Research. 16,89 116.

Meyer, D. R., Phillips, E., \& Maritato, N. L. (1991). The effect of replacing income tax deductions for children with children's allowances: A microsimulation. Journal of Family Issues, 12, 467-491.

Mittelman, M. S., Ferris, S. H., Steinberg, G., Shulman, E., Mackell, J. A., Ambinder, A., \& Cohen, J. (1993). An intervention that delays institutionalization of Alzheimer's disease patients: Treatment of spousecaregivers. Gerontologist, 33, 730-740.

Nugent, W. R. (1991). An experimental and qualitative analysis of a cognitive-behavioral intervention for anger. Social Work Research \& Abstracts, 27(3), 3-8.

Nugent, W. R. (1993). A series of single case design clinical evaluations of an Ericksonian hypnotic intervention used with clinical anxiety. Journal of Social Service Research, 17, 41-69

Nugent, W. R., Carpenter, D., \& Parks, J. (1993). A statewide evaluation of family preservation and family reunification services. Research on Social Work Practice, 3, 40-65.

O'Neal, G. S. (1993). Preventing conflict: Encouraging collaboration among students, faculty, and family. Social Work in Education, 15, 83-89.

Orgnero, M. I., \& Rodway, M. R. (1991). AIDS and social work treatment: A single-system analysis. Health \& Social Work, 16, 123-141.

Pillemer, K., \& Hudson, B. (1993). A model abuse prevention program for nursing assistants. Gerontologist, 33, 128131 .

Ramanathan, C. S. (1992). EAP's response to personal stress and productivity: Implications for occupational social work. Social Work, 37, 234-239.

Raynor, P., \& Vanstone, M. (1994). Probation practice, effectiveness and the non-treatment paradigm. British Journal of Social Work, 24, 387-404.

Reid, W. J., Bailey-Dempsey, C. A., Cain, E., Cook, T. V., \& Burchard, J. D. (1994). Cash incentives versus case management: Can money replace services in preventing school failure? Social Work Research, 18, 227-236.

Ressler, L. E. (1991). Improving elderly recall with bimodal presentation: A natural experiment of discharge planning. Gerontologist, 31, 364-370.

Richey, C. A., \& Hodges, V. G. (1992). Empirical support for the effectiveness of respite care in reducing caregiver burden: A single-case analysis. Research on Social Work Practice. 2, 143-160.

Rickard, H. C., Scogin, F., \& Keith, S. (1994). A one-year followup of relaxation training for elders with subjective anxiety. Gerontologist, 34, 121-122.

Rife, J. C., \& Belcher, J. R. (1994). Assisting unemployed older workers to become reemployed: An experimental evaluation. Research on Social Work Practice, 4, 3-13.

Rosen, A. (1993). Correction of workers' personal versus environmental bias in formulation of client problems. Social Work Research \& Abstracts, 29(4), 12-17.

Rosenthal, J. A., \& Glass, G. V. (1990). Comparative impacts of alternatives to adolescent placement. Journal of Social Service Research, 13, 19-37.

Rubin, A. (1991). The effectiveness of outreach counseling and support groups for battered women: A preliminary evaluation. Research on Social Work Practice, I, 332357.
Rubin, A. B., Franklin, C., \& Selber, K. (1992). Integrating research and practice into an interviewing skills project: An evaluation. Journal of Social Work Education, 28, 141-152.

Saunders, R. I., \& Saunders, D. N. (1993). Social work practice with a bulimic population: A comparative evaluation of purgers and nonpurgers. Research on Social Work Practice, 3, 123-136.

Schilling, R. F., Koh, N., Abramovitz, R., \& Gilbert, L. (1992). Bereavement groups for inner-city children. Research on Social Work Practice, 2, 405-419.

Scott, M. J., \& Stradling, S. G. (1991). The cognitivebehavioural approach with depressed clients. British Journal of Social Work, 21, 533-544.

Segal, S. P., \& Hwang, S.-D. (1994). Licensure of sheltered-care facilities: Does it assure quality? Social Work, 39, 124-131.

Shiels, L., \& Butler, W. (1992). The development of a stress management and relaxation group in an acute teaching hospital. Australian Social Work, 45, 27-30.

Shulman, L. (1993). Developing and testing a practice theory: An interactional perspective. Social Work, 38, 91-97.

Snow, D. J. (1992). Marital therapy with parents to alleviate behavioral disorders in their children. Research on Social Work Practice, 2, 172-183.

Stevenson, K. M., Leung, P., \& Cheung, K.-F. M. (1992). Competency-based evaluation of interviewing skills in child sexual abuse cases. Social Work Research \& Abstracts, 28(3), 11-16.

Stosny, S. (1994). "Shadows of the Heart": A dramatic video for the treatment resistance of spouse abusers. Social Work, $39,686-694$.

Subramanian, K. (1991). Structured group work for the management of chronic pain: An experimental investigation. Research on Social Work Practice, 1, 32-45.

Sullivan, R., \& Clancy, T. (1990). An experimental evaluation of interdisciplinary training in intervention with sexually abused adolescents. Health \& Social Work, 15, 207-214.

Tolson, E. R., McDonald, S., \& Moriarty, A. R. (1992). Peer mediation among high school students: A test of effectiveness. Social Work in Education, 14, 86-93.

Toseland, R. W. (1990). Long-term effectiveness of peer-led and professionally led support groups for caregivers. Social Service Review, 64, 308-327.

Toseland, R. W., Labrecque, M. S., Goebel, S. T., \& Whitney, M. H. (1992). An evaluation of a group program for spouses of frail elderly veterans. Gerontologist, 32, 382390.

Toseland, R. W., Rossiter, C. M., Peak, T., \& Smith, G. C. (1990). Comparative effectiveness of individual and group interventions to support family caregivers. Social Work, $35,209-217$.

Turnbull, J. E., Galinsky, M. J., Wilner, M. E., \& Meglin, D. E. (1994). Designing research to meet service needs: An evaluation of single-session groups for families of psychiatric patients. Research on Social Work Practice, 4, 192-207.

Umbreit, M. S. (1994). Crime victims confront their offenders: The impact of a Minneapolis mediation program. Research on Social Work Practice, 4, 436-447.

Vera, M. I. (1990). Effects of divorce groups on individual adjustment: A multiple methodology approach. Social Work Research \& Abstracts, 26(3), 11-20.

Vera, M. I. (1993). Group therapy with divorced persons: Empirically evaluating social work practice. Research on Social Work Practice, 3, 3-20.

Walsh, J. (1994). Social support resource outcomes for the clients of two assertive community treatment teams. Research on Social Work Practice, 4, 448-463.

Wells, K., \& Whittington, D. (1993). Child and family functioning after intensive family preservation services. Social Service Review, 67, 56-83. 
Wodarski, J. S., \& Bordnick, P. S. (1994). Teaching adolescents about alcohol and driving: A 2-year follow-up study. Research on Social Work Practice, 4, 28-39.

York, R. O. (1994). The influence of optimal decision participation upon decision outcome in human service organizations. Journal of Social Service Research, 19, 139-160.

Original manuscript received January 25, 1995 Final revision received October 20. 1995 Accepted November 15, 1995

The author gratefully acknowledges Nancy L. Richter and Therese A. Andre, who independently coded data from the studies in this review. Critical commentary was provided by Eve P. Smith, Michael J. Holosko, Wilfred A. Gallant, all of the University of Windsor's School of Social Work, and five anonymous reviewers.

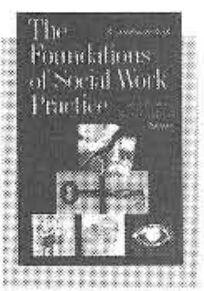

\section{The Foundations of} Social Work Practice A Graduate Text

Carol H. Meyer and Mark. A. Mattaini, Editors

A to meet the requirements for a graduate foundation course. Provides a base for graduate social work students and prepares them for future courses and experiences.

ISBN: $0.87101-237.5 \cdot$ Item \#2375 • 1995 $\$ 34.95$

To order, send $\$ 38.45$ (includes $\$ 3.50$ postage and handling) to NASW Press, P.O. Box 431, Annapolis JCT, MD 20701 USA. Or call toll free: $1-800-227-3590$. In the Metro Wash. DC area, call $301-317-8688$. Or...fax your order by calling 301-206-7989!

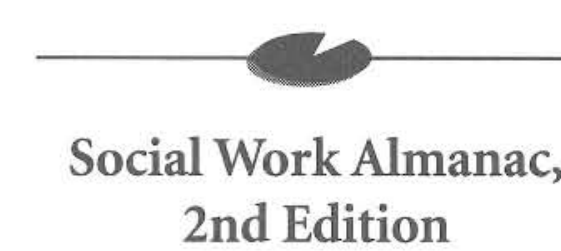

by LEON GINSBERG

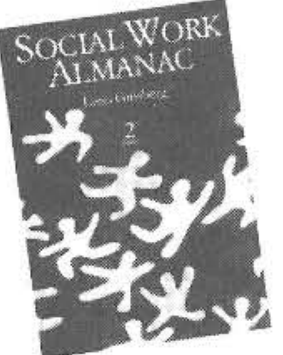

Social Work Almanac, the profession's most comprehensive sourcebook, is now $61 \%$ larger, with $69 \%$ more tables and $73 \%$ more figures. The latest

facts have been rigorously researched and compiled to update the second edition of this practical compendium of statistical data related to social welfare. The new second edition makes it even easier to find social work facts. A useful tool for identifying trends, substantiating reports, writing papers, preparing funding proposals, and more.

(Also available on the Social Work Reference Library CD-ROM. Call 1-800227-3590 for more information.)

Contents: Basic Demographic Data on the U.S. Population * Children - Crime and Delinquency • Health and Mortality Statistics - Education Mental Health - Older Adults - Social Welfare, Economic Assistance, Housing, and Homelessness - Social Work Professional Issue, - Reference - Index

ISBN: $0-87101-248-0 \cdot$ Item $\# 2480+1995 \cdot 391$ pages $-\$ 34.95$

To order, send $\$ 38.45$ (includes $\$ 3.50$ postage and handling) to NASW Press, P.O. Box 431, Annapolis JCT, MD 20701 USA. Credit card orders call 1-800-227-3590 (in metro Wash., DC, call 301-317-8688) or fax your order by calling 301-206-7989.

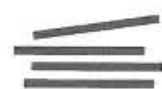

NASW PRESS 